\title{
Analisa Performa Penggunaan Feature Selection untuk Mendeteksi Intrusion Detection Systems dengan Algoritma Random Forest Classifier
}

\author{
Setiawan Budiman*, Andi Sunyoto, Asro Nasiri \\ Magister Teknik Informatika, Universitas AMIKOM Yogyakarta \\ Jl. Ring Road Utara. Sleman, Yogyakarta, Indonesia \\ *e-mail: setiawan.1267@students.amikom.ac.id
}

(received: 30 Juli 2021, revised: 5 September 2021, accepted: 28 September 2021)

\begin{abstract}
Abstrak
Semakin penting koneksi data melalui Internet membuat kebutuhan akan keamanan jaringan data semakin meningkat. Salah satu tools yang penting adalah Intrusion detection systems (IDS). Salah satu hal yang menjadi masalah dari penggunaan IDS adalah performan kecepatan untuk mendeteksi data yang semakin banyak dalam waktu yang singkat. Dalam penelitian ini kami akan melakukan analisa perbandingan performa IDS menggunakan features selection dengan algoritma Random Forest Classifier yang disimulasikan pada dataset UNSW-NB15, yaitu dataset simulasi serangan pada jaringan network yang dikembangan oleh Nour Moustafa \& Jill Slay dari University of New South Wales pada Australian Defence Force Academy. Tujuan dari penelitian ini adalah mempercepat waktu proses Intrusion detection systems dengan machile learning. Penelitian dilakukan dengan 2 tahap, yaitu tahap pertama tanpa features selection dan tahap kedua dengan features selection ExtraTreesClassifier. Masing-masing tahap dilakukan dengan beberapa kali pengujian dengan persentasi testing dan training data yang berbeda. Hasil penelitian menunjukan bahwa penggunaan features selection dapat mempercepat waktu proses pendeteksian dengan menggunakan Random Forest Classifier, walaupun ada sedikit penurun akurasi dibawah $1 \%$.
\end{abstract}

Kata kunci: feature selection, random forest, ids, machine learning

\begin{abstract}
Internet data connection is very important, therefore it will increasing the security issues. One of the important tools is Intrusion detection systems (IDS). The main problems of using IDS is the speed performance to detect more and more data in a short time. In this study, we will perform a comparative analysis of IDS performance using features selection with the Random Forest Classifier algorithm which is simulated on the UNSW-NB15 dataset, which is work as the attack simulation dataset on the network developed by Nour Moustafa \& Jill Slay from the University of New South Wales at the Australian Defense Force Academy. The purpose of this research is to speed up the processing time of Intrusion detection systems with machile learning. The research was conducted in 2 stages, the first stage without features selection and the second stage with features selection. Each stage is carried out with several study using different percentages of testing and training data. The results showed that by using features selection, it can speed up the detection process time using the Random Forest Classifier, although there is a slight decrease in accuracy below $1 \%$.
\end{abstract}

Keywords: feature selection, random forest, ids, machine learning

\section{Pendahuluan}

Dengan semakin berkembangnya koneksi Internet di seluruh dunia, maka saat ini semakin banyak juga serangan yang terjadi pada system jaringan Internet. Serangan pada Internet dilakukan untuk mendapatkan keuntungan baik secara finansial maupun keuntungan lainnya seperti permasalahan sosial dan politik. Solusi untuk permasalahan ini adalah dengan dikembangkannya teknologi intrusion detection systems (IDS), firewall dan beberapa tools lainnya. Penelitian ini akan 
berfokus pada penggunaan intrusion detection systems (IDS) untuk mendeteksi apakah ada komunikasi data yang anomali atau mencurigakan. Dengan adanya informasi serangan dari IDS, system firewall dapat segera melakukan tindakan preventif dengan cara melakukan blocking pada aktivitas network tersebut. Saat ini penggunaan IDS semakin diperlukan terutama untuk jaringan komunikasi sibuk yang terhubung ke seluruh dunia. Dengan semakin banyaknya data yang harus di pelajari oleh IDS, maka salah satu kunci keberhasilannya adalah akurasi dan kecepatan waktu prosesnya[1].

Saat ini sudah tersedia banyak dataset dengan kualitas yang baik untuk mewakili hasil kerja dari sebuah IDS. Pada study ini digunakan dataset UNSW-NB15 yang dikembangan oleh Nour Moustafa \& Jill Slay dari University of New South Wales pada Australian Defence Force Academy[2]. Dataset ini memiliki sekitar 2 juta data yang mewakili 9 jenis serangan dengan total 47 features.

Penelitian ini akan melakukan sebuah analisa untuk membandingkan kecepatan waktu proses pendeteksian data dari IDS antara menggunakan features selection dibandingkan dengan tidak menggunakan feature selection. Basis dari penelitian ini adalah menggunakan algoritma Random Forest Classifier, termasuk untuk feature selection dan klasifikasinya. Dari beberapa penelitian disebutkan bawah penggunaan Random Forest Classifier memberikan hasil yang lebih baik untuk permodelan pada Intrusion Detection Systems seperti penelitian yang dilakukan dengan judul A Survey of Random Forest Based Methods for Intrusion Detection Systems[3]. Random forest akan membuat permodelan dengan beberapa decision tree. Feature selection yang digunakan adalah dengan menggunakan library sklearn ExtraTreesClassifier yang berbasis pada ensemble learning dengan menggunakan decision tree.

\section{Tinjauan Literatur}

\subsection{Pengembangan Intrusion Detection Systems}

Beberapa penelitian sejenis yang telah dilakukan menggunakan data intrusion detection systems (IDS) memiliki tujuan utama yang sama, yaitu dengan menganalisa serta meningkatkan performa machine learning tersebut. Penelitian dengan judul Performance Analysis of Intrusion Detection Systems Using a Feature Selection Method on the UNSW-NB15 Dataset[4] dilakukan untuk memberikan peningkatan hasil dengan menggunakan XGBoost-based feature selection sebelum melakukan deteksi dengan machine learning Support Vector Machine (SVM), $k$-Nearest-Neighbour (kNN), Logistic Regression (LR), Artificial Neural Network (ANN) dan Decision Tree (DT). Hasil penelitian tersebut adalah features selection XGBoost-based dapat memberikan hasil yang lebih baik pada machine learning Decession Tree (DT). Penelitian lainnya dengan judul Network Intrusion Detection: A Comparative Study Using State-of-the-art Machine Learning Methods[5] telah dilakukan untuk mengetahui hasil penggunaan dataset IDS yang dideteksi dengan beberapa algoritma machine learning yaitu Logistic regression, SGD, Light GBM, XG-Boost, DNN, Stacked classifier. Dan hasil penelitian tersebut adalah bahwa Gradient Boosting Decision Tree akan memberikan hasil yang lebih baik. Penggunaan beberapa algoritma machine learning dengan metode ensemble methods dapat memberikan hasil akurasi yang lebih baik dibandingkan menggunakan single klasifikasi. Hal ini dapat dilihat dari hasil penelitian dengan judul Use The Ensemble Methods When Detecting DoS Attacks in Network Intrusion Detection[6].

\subsection{Dataset Penelitian}

Ada beberapa jenis dataset yang dapat digunakan pada penelitian yang berhubungan dengan intrusion detection systems (IDS). Salah satu yang memiliki kelengkapan data adalah UNSW-NB15. Dataset ini dapat didownlaod dari www.kaggle.com. Penelitian dengan judul Analysis of UNSWNB15 Dataset Using Machine Learning Classifiers[7] telah dilakukan yang tujuannya untuk mendeteksi hasil machine learning dengan beberapa algoritma, yaitu Naive Bayes, Logistic Regression, SMO, J48 dan Random Forest. Dan Random Forest dapat memberikan hasil akurasi yang paling baik dibanding lainnya. Pada beberapa penelitian lain, juga dilakukan dengan menggunakan dataset lain seperti dataset KDDCUP99 tetapi dataset ini sudah mulai banyak ditinggalkan karena out of date, karena sudah tidak dapat mewakili perkembangan simulasi IDS dengan berbagai macam kasus dan teknik serangan yang lebih modern[8]. Dataset lain yang bisa digunakan pada sebuah 
penelitian berbasis IDS adalah NSL-KDD. Ketiga dataset ini sudah dilakukan perbandingan menggunakan machine learning dengan algoritma Deep Neural Network (DNN) dan hasilnya samasama memberikan akurasi kurang lebih mencapai 90\%[9].

\subsection{Feature Selection}

Pada era IoT dan aplikasi berbasis web-based, produksi berbagai macam data penjadi sangat cepat dan ini mengakibatkan terbentuknya big data yang terus bertambah secara otomatis. Hal ini menyebabkan akan ditemukan banyak data noise yang tidak berguna, redundancy dan membutuhkan teknologi komputasi yang besar untuk memproses data. Oleh karena itu diperlukan metode feature selection untuk mengurangi jumlah features yang noisy, redundant dan irrelevant data[10]. Feature selection juga digunakan pada penelitian dengan judul Intrusion Detection Model Using Fusion Of Chi-Square Feature Selection And Multi Class SVM[11]. Dataset IDS yang digunakan adalah NSLKDD. Hasil dari penelitian ini terlihat bahwa dengan menggunakan Chi-Square feature selection dapat memberikan percepatan waktu proses dalam algoritma machine learning Multi Class SVM. Selain itu juga terdapat Feature Selection dengan menggunakan Chi-Square yang berfokus pada pendeteksian serangan DDoS dengan judul Peningkatan Akurasi Pendeteksian Serangan DDoS Menggunakan Multiclassifier Ensemble Learning dan Chi-Square[12] dengan mengunakan dataset NSL-KDD. Feature selection semakin banyak digunakan untuk melakukan optimalisasi sebelum dilakukan analisa akhir, salah satunya pada penelitian menggunakan Naive Bayes Feature Selection yang kemudian dilanjutkan dengan klasifikasi machine learning menggunakan algoritma SVM telah dilakukan dengan judul An effective intrusion detection approach using SVM with nä̈ve Bayes feature embedding[13].

\subsection{Random Forest}

Random forest adalah salah satu teknik klasifikasi (supervised classification) yang banyak digunakan diberbagai macam penelitian dan model kasus. Ini adalah sebuah proses pengambilan keputusan berdasarkan pencabangan pohon atau decision tree. Tiap cabang berisi tentang pertanyaan untuk memecahkan sebuah keputusan dari jumlah pencabangan ideal[14] $\square$. Terdapat beberapa penelitian yang menyebutkan bahwa Random Forest dapat memberikan hasil akurasi yang baik pada penelitian dengan judul A Comparative Analysis of Logistic Regression, Random Forest and KNN Models for the Text Classification [15]. Penelitian tersebut dilakukan untuk mengetahui bagaimana akurasi jika dibandingkan dengan KNN dan Logistic Regression. Hasilnya didapatkan bahwa Random Forest masih lebih baik dibandingkan dengan KNN, tetapi pada penelitian tersebut Logistic Regression masih memiliki akurasi terbiak, oleh karena itu perlu dibuat penelitian lebih lanjut yang mencari parameter terbaik agar Random Forest menjadi lebih akurat. Sedangkan penelitian yang dilakukan dengan judul Use of Random Forest in The Identification of Important Variables[16] berfokus pada pencarian variable yang lebih penting dengan algoritma Random Forest, pada penentuan data crude oil yang dilihat berdasarkan variable yang paling sering digunakan dari pencabangan pohon tersebut. Random Forest juga berguna untuk mengolah klasifikasi big data dan IoT yang telah dilakukan pada penelitian dengan judul Random Forest for Big Data Classification in The Internet of Things Using Optimal Features[17] yang dilakukan pada bidang kesehatan yang menggunakan data kesehatan pasien. Pengunaan IoT untuk mengumpulkan data dapat mengakibatkan feedback data yang besar, itu sebabnya penggunaan machine learning dengan alrogitma Random Forest dapat membantu klasifikasi data secara akurat. Penelitian lain yang berhubungan dengan IoT pada bagian wireless sensor network dilakukan dengan judul Fault Detection in Wireless Sensor Networks through the Random Forest Classifie[18], penelitian ini dilakukan untuk mendapatkan hasil klasifikasi terbaik antara beberapa jenis algoritma seperti SVM, RF, SGD, MLP, CNN, dan PNN untuk memberikan data kegagalan dan kerentanan yang dibutuhkan untuk memperbaiki dengan system update dan peningkatan kinerja. Hasil yang didapatkan bahwa Random Forest (RF) memberikan hasil yang terbaik dibanding algoritma lainnya.

\section{Metode Penelitian}

Penelitian ini menggunakan metode yang bersifat kuantitatif dan komparatif. Hal ini dilakukan karena akan membandingkan beberapa data dengan bahasa program Python yang dijalan dengan 
menggunakan beberapa library seperti sklearn dan library pendukung lainnya. Penelitian ini akan melakukan analisis pada suatu jaringan apakah kondisnya normal atau anomali (bermasalah).

Dataset yang digunakan adalah UNSW-NB15 yang tersedia di Kaggel oleh Nour Moustafa dan Jill Slay di University of New South Wales yang dikembangkan bersama Australian Centre for Cyber Security (ACCS) untuk membuat simulasi serangan meggunakan software IXIA PerfectStorm tool. Dataset ini memiliki 47 features dengan 9 jenis serangan. Dari seluruh serangan tersebut, dapat di kategorikan dalam 2 besar yaitu kondisi jaringan normal atau anomali[2] $\square$.

Langkah yang dilakukan dalam penelitian ini adalah dengan menguplaod data csv UNSW-NB15 agar dapat dibaca oleh Python. Dataset yang digunakan adalah gabungan dari UNSW-NB15 training dan testing dengan total 257.673 baris. Hal ini dilakukan agar data penelitian ini memiliki data yang cukup besar. Proses berikutnya adalah konversi beberapa features dari object menjadi numeric agar dapat dilakukan proses classfication. Setelah itu penelitian ini akan dilakukan menjadi 2 bagian, yaitu pertama dengan full features dan yang kedua menggunakan feature selection. Tiap bagian akan disajikan dalam tabel perbandingan hasil akhir dari confussion matrix. Pada proses pemilihan feature menggunakan Feature Selection Extra Trees Classifier pada library sklearn.ensemble ExtraTreesClassifier, yaitu menentukan feature selection yang berbasis pada RandomForestClassifier, untuk mendapatkan features dengan kontribusi sedikit terhadap hasil label yang dapat memberikan akibat overfit serta mempengaruhi lamanya waktu proses akibat melakukan analisa pada feature yang tidak berpengaruh banyak pada hasil classification. Selanjutnya dilakukan pembagian data untuk testing dan training yaitu dengan komposisi 90\%:10\%, 80\%:20\%, 70\%:30\%, 60\%:40\%, 50\%:50\%, sehingga total akan dilakukan dengan 5 set data yang dibagi secara acak. Feature yang ada pada data traning dan testing akan dipilih sesuai hasil output dari proses Feature Selection Extra Trees Classifier. Langkah berikutnya adalah melakukan prediksi dengan menggunakan Random Forest Classifier untuk menentukan hasil accuracy dan precission dengan menggunakan Confusion Matrix.

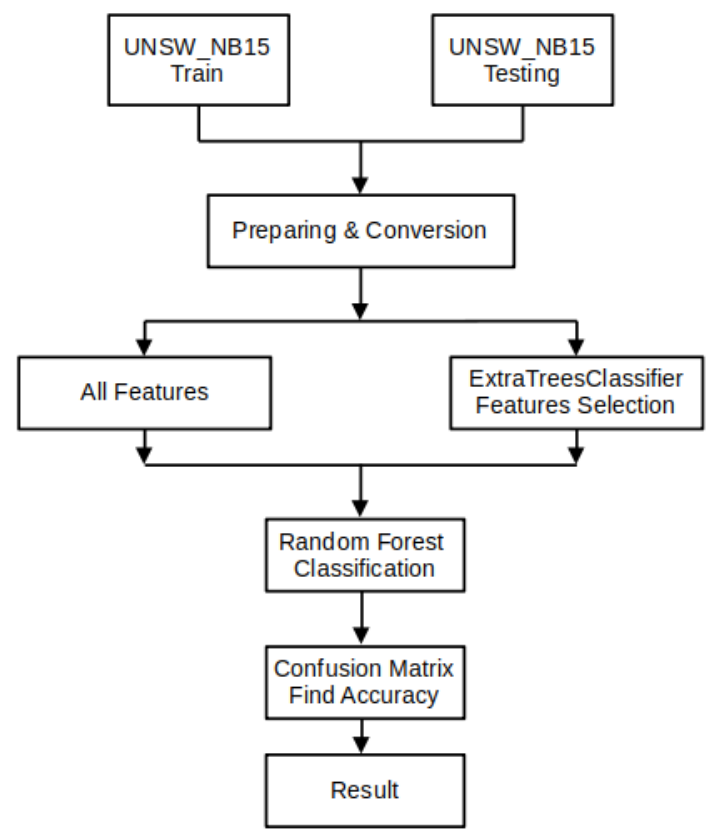

Gambar 1. Alur Penelitian

\section{$4 \quad$ Hasil dan Pembahasan}

Hasil dari penelitian ini kami tuliskan dapat bentuk beberapa tabel dan grafik agar memudahkan proses membaca hasil. Proses penelitian ini dibagi menjadi 2 bagian, yaitu proses awal sampai akhir dengan menggunakan semua feature sebanyak 41 yang ada pada dataset UNSW-NB15 dengan jumlah 257.673 baris. Setelah dilakukan konversi dengan sklearn.preprocessing LabelEncoder, maka 
hasilnya seluruh type object telah diubah menjadi type integer. Selanjutnya dilakukan penghapusan features bertype object, sehingga hasilnya dapat dilihat pada tabel 1.

Tabel 1. Hasil Konversi Features

\begin{tabular}{|c|c|c|c|c|c|}
\hline No. & Feature & Type & No. & Feature & Type \\
\hline 0 & id & float64 & 22 & ackdat & float64 \\
\hline 1 & spkts & int64 & 23 & smean & int64 \\
\hline 2 & dpkts & int64 & 24 & dmean & int64 \\
\hline 3 & sbytes & int64 & 25 & trans_depth & int64 \\
\hline 4 & dbytes & int64 & 26 & response_body_len & int64 \\
\hline 5 & rate & float64 & 27 & ct_srv_src & int64 \\
\hline 6 & sttl & int64 & 28 & ct_state_ttl & int64 \\
\hline 7 & $\mathrm{dttl}$ & int64 & 29 & ct_dst_ltm & int64 \\
\hline 8 & sload & float64 & 30 & ct_src_dport_ltm & int64 \\
\hline 9 & dload & float64 & 31 & ct_dst_sport_ltm & int64 \\
\hline 10 & sloss & int64 & 32 & ct_dst_src_ltm & int64 \\
\hline 11 & dloss & int64 & 33 & is_ftp_login & int64 \\
\hline 12 & sinpkt & float64 & 34 & ct_ftp_cmd & int64 \\
\hline 13 & dinpkt & float64 & 35 & ct_flw_http_mthd & int64 \\
\hline 14 & sjit & float64 & 36 & ct_src_ltm & int64 \\
\hline 15 & djit & float64 & 37 & ct_srv_dst & int64 \\
\hline 16 & swin & int64int64 & 38 & is_sm_ips_ports & int64 \\
\hline 17 & stcpb & int64int64 & 39 & proto_n & int64 \\
\hline 18 & dtcpb & int64int64 & 40 & service_n & int64 \\
\hline 19 & dwin & int64 & 41 & state_n & int64 \\
\hline 20 & tcprtt & float64 & & & \\
\hline 21 & synack & float64 & & & \\
\hline
\end{tabular}

Pada bagian pertama, penulis tidak melakukan proses feature selection, sehingga semua 41 features pada tabel 1 akan digunakan. Data UNSW-NB15 dibagi menjadi menjadi training dan testing. Proses ini akan dilakukan sebanyak 5 pembagian yaitu dengan komposisi 90\%:10\%, 80\%:20\%, 70\%:30\%, 60\%:40\%, 50\%:50\%. Langkah berikutnya adalah melakukan klasifikasi dengan Random Forest, percobaan dilakukan masing masing sebanyak 4 kali dan didapatkan hasil akurasi terbaik sebagai yang pada dilihat pada tabel 2 .

Pada bagian kedua, agar data yang digunakan tetap konsisten, penelitian ini dilanjutkan dengan menggunakan komposisi dataset yang sudah dibagi sebelumnya untuk dimasukkan pada pemilihan feature selection. Hasil output dari proses Feature Selection Extra Trees Classifier didapatkan pengurangan sebanyak 13 features. Selanjutnya program akan menghilangkan ke 13 feature yang tidak mempunyai pengaruh dengan nilai dibawah 0.01 , seperti yang terlihat pada tabel 3 . Kemudian 
dilanjutkan lagi untuk proses klasifikasi dengan Random Forest yang dilakukan sebanyak 4 kali. Hasil terbaiknya dituliskan pada tabel 2. Penulis menentukan batas nilai kurang 0.01 untuk dihapus karena hasil output dari Feature Selection Extra Trees Classifier rata-rata berkisar antara dari 0.1 sampai 0.01, dimana semakin kecil jarak selisihnya, maka semakin tidak berguna feature tersebut. Contoh feature yang dihapus memiliki nilai output $0.00804461,0.00770632$ dan 0.00630018 .

Tabel 2. Hasil Klasifikasi Random Forest Dengan dan Tanpa Feature Selection (FS)

\begin{tabular}{cccccc}
\hline & & \multicolumn{2}{c}{ Akurasi } & \multicolumn{2}{c}{ Waktu Proses } \\
\cline { 3 - 6 } No. & Komposisi & Tanpa FS & Dengan FS & $\begin{array}{c}\text { Tanpa } \\
\text { FS }\end{array}$ & Dengan FS \\
\hline 1. & $90 \%: 10 \%$ & $95.31 \%$ & $95.24 \%$ & $50.08 \mathrm{~s}$ & $45.13 \mathrm{~s}$ \\
2. & $80 \%: 20 \%$ & $95.12 \%$ & $95.06 \%$ & $45.52 \mathrm{~s}$ & $40.96 \mathrm{~s}$ \\
3. & $70 \%: 30 \%$ & $95.07 \%$ & $95.02 \%$ & $39.94 \mathrm{~s}$ & $36.17 \mathrm{~s}$ \\
4. & $60 \%: 40 \%$ & $94.91 \%$ & $94.90 \%$ & $39.35 \mathrm{~s}$ & $33.00 \mathrm{~s}$ \\
5. & $50 \%: 50 \%$ & $94.78 \%$ & $94.76 \%$ & $27.70 \mathrm{~s}$ & $24.86 \mathrm{~s}$ \\
\hline
\end{tabular}

Tabel 3. Feature Dengan Kontribusi Paling Sedikit

\begin{tabular}{llllll}
\hline No. & Feature & Type & No. & Feature & Type \\
\hline 0 & ct_ftp_cmd & int64 & 8 & dbytes & int64 \\
1 & is_ftp_login & int64 & 9 & dinpkt & int64 \\
2 & response_body_len & int64 & 10 & djit & float64 \\
3 & ct_flw_http_mthd & int64 & 11 & sjit & float64 \\
4 & trans_depth & int64 & 12 & dpkts & int64 \\
5 & spkts & int64 & & & \\
6 & dloss & int64 & & & \\
7 & sloss & int64 & & & \\
& & & & &
\end{tabular}

Untuk memberikan gambaran hasil perbandingan yang lebih mudah, maka data output dari penelitian menggunakan dataset UNSW-NB15 dengan komposisi yang terdiri dari 5 set pembagian data training dan testing yaitu 90\%:10\%, 80\%:20\%, 70\%:30\%, 60\%:40\%, 50\%:50\% disajikan juga dalam bentuk grafik yang dapat dilihat pada gambar 2 untuk perbandingan akurasi dan pada gambar 3 untuk perbandingan waktu saat tanpa menggunakan feature selection dan dengan menggunakan feature selection. Untuk hasil akurasi terbaik didapatkan dengan menggunakan data training sebanyak $90 \%$ dan data testing sebanyak 10\% yang terlihat pada gambar 4 di bawah ini.

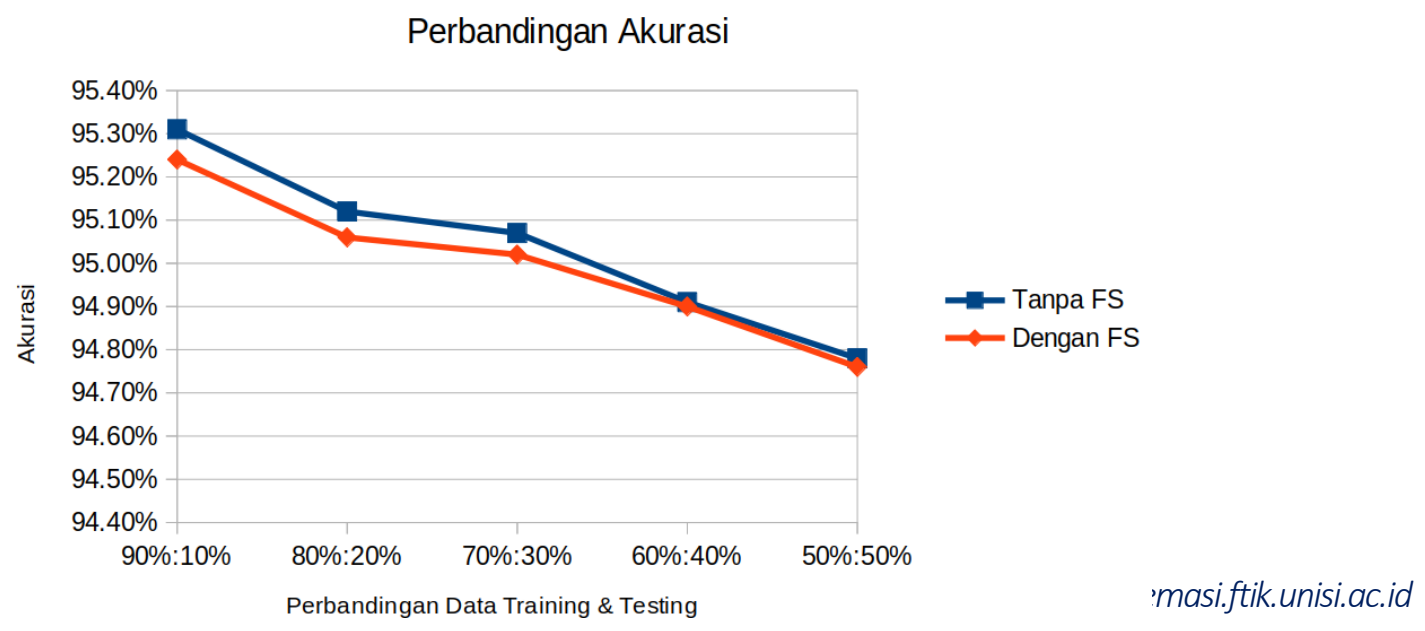




\section{Gambar 2. Perbandingan Akurasi Antara Tanpa dan Dengan Features Selection}

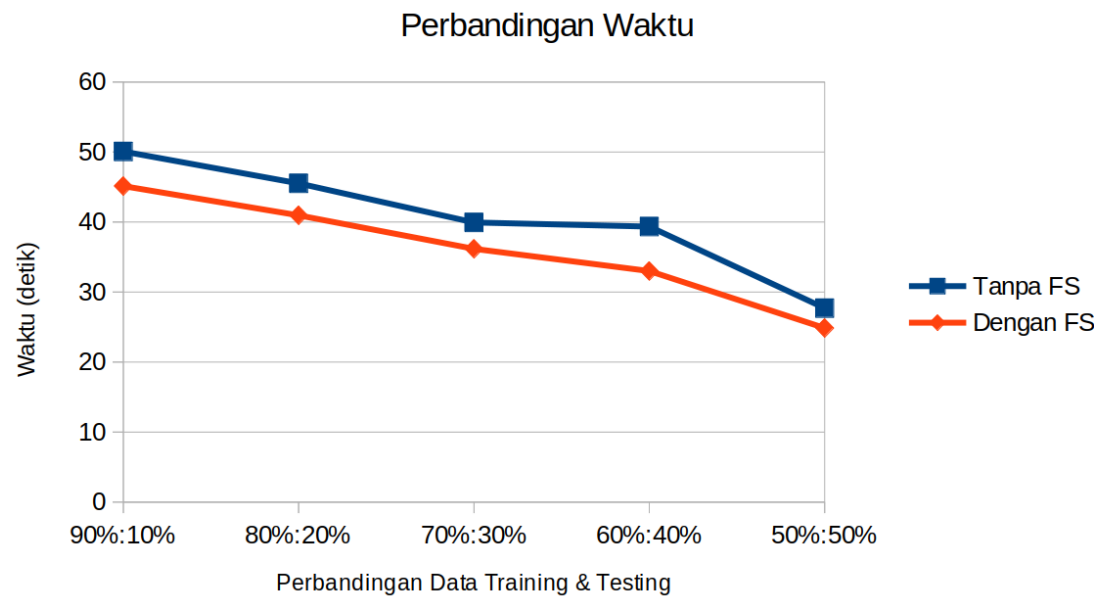

Gambar 3. Perbandingan Waktu Proses Antara Tanpa dan Dengan Features Selection

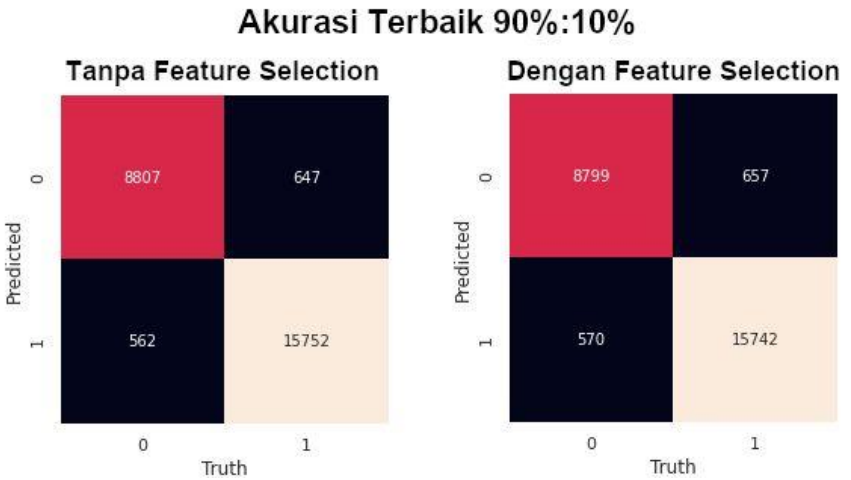

Gambar 4. Akurasi Terbaik Dengan dan Tanpa Feature Selection

Dari hasil tabel penelitian ini, terlihat bahwa akurasi terbaik didapatkan ada data training sebanyak $90 \%$ dan data testing sebanyak $10 \%$ karena semakin banyak data training yang diberikan, maka semakin banyak contoh data yang dapat dijadikan acuan oleh machine learning untuk menetukan kesalahan pendeteksian. Hasil penelitian didapatkan bahwa waktu proses dengan menggunakan feature selection menjadi lebih cepat. Tetapi ada beberapa features penting yang tercampur dengan data noise, namun jumlahnya sangat sedikit sehingga tidak dapat dibedakan saat diproses dengan Feature Selection Extra Trees Classifier. Akibatnya hasil akurasinya menjadi sedikit berkurang namun sangat kecil sekali, hanya kurang dari $1 \%$. Oleh karena itu, penggunaan feature selection masih memberikan manfaat yang lebih baik dibandingkan tanpa feature selection, yaitu pada kecepatan proses yang lebih baik.

\section{Kesimpulan}

Penelitian ini dilakukan untuk membandingkan performa dari algoritma machine learning Random Forest dengan menggunakan feature selection atau tanpa feature selection. Dataset yang digunakan adalah UNSW-NB15 dengan kategori label normal atau anomali. Jumlah dataset yang digunakan adalah 257.673 record. Proses penelitian dilakukan dengan beberapa kali ujicoba menggunakan perbandingan data traning dan testing sebanyak 90\%:10\%, 80\%:20\%, 70\%:30\%, 60\%:40\%, 50\%:50\%. Hasil yang didapatkan bahwa penggunaan feature selection berbasis decision tree ExtraTreesClassifier akan memberikan waktu proses yang lebih cepat dibandingkan tanpa feature selection, walaupun terdapat penurunan hasil akurasi kurang dari $1 \%$ jika dibandingkan tanpa feature selection. Peningkatan kecepatan ini memberikan dampak yang lebih penting untuk memberikan efisiensi waktu pada deteksi data IDS dan berkurangnya load kinerja hardware. Untuk hasil akurasi terbaik didapatkan dengan menggunakan data training sebanyak $90 \%$ dan data testing sebanyak $10 \%$. Untuk penelitian yang akan datang, penelitian dapat menggunakan feature selection jenis lainnya untuk mendapatkan hasil kecepatan dan akurasi yang lebih baik. 


\section{Referensi}

[1] I. Sumaiya Thaseen, J. Saira Banu, K. Lavanya, M. Rukunuddin Ghalib, and K. Abhishek, “An integrated intrusion detection system using correlation-based attribute selection and artificial neural network," Trans. Emerg. Telecommun. Technol., vol. 32, no. 2, pp. 1-15, 2021, doi: 10.1002/ett.4014.

[2] N. Moustafa and J. Slay, "UNSW-NB15: A comprehensive data set for network intrusion detection systems (UNSW-NB15 network data set)," 2015 Mil. Commun. Inf. Syst. Conf. MilCIS 2015 - Proc., no. November, 2015, doi: 10.1109/MilCIS.2015.7348942.

[3] P. A. A. Resende and A. C. Drummond, "A survey of random forest based methods for intrusion detection systems," ACM Comput. Surv., vol. 51, no. 3, 2018, doi: 10.1145/3178582.

[4] S. M. Kasongo and Y. Sun, "Performance Analysis of Intrusion Detection Systems Using a Feature Selection Method on the UNSW-NB15 Dataset," J. Big Data, vol. 7, no. 1, 2020, doi: 10.1186/s40537-020-00379-6.

[5] M. Rai and H. L. Mandoria, "Network Intrusion Detection: A comparative study using stateof-the-art machine learning methods," IEEE Int. Conf. Issues Challenges Intell. Comput. Tech. ICICT 2019, pp. 0-4, 2019, doi: 10.1109/ICICT46931.2019.8977679.

[6] H. Thanh and T. Lang, "Use the ensemble methods when detecting DoS attacks in Network Intrusion Detection Systems," EAI Endorsed Trans. Context. Syst. Appl., vol. 6, no. 19, p. 163484, 2019, doi: 10.4108/eai.29-11-2019.163484.

[7] A. Dickson and C. Thomas, Analysis of UNSW-NB15 Dataset Using Machine Learning Classifiers, vol. 1366. Springer Singapore, 2021.

[8] D. G. Mogal, S. R. Ghungrad, and B. B. Bhusare, "NIDS using Machine Learning Classifiers on UNSW-NB15 and KDDCUP99 Datasets," Ijarcce, vol. 6, no. 4, pp. 533-537, 2017, doi: 10.17148/ijarcce.2017.64102.

[9] S. Choudhary and N. Kesswani, "Analysis of KDD-Cup'99, NSL-KDD and UNSW-NB15 Datasets using Deep Learning in IoT," Procedia Comput. Sci., vol. 167, no. 2019, pp. 15611573, 2020, doi: 10.1016/j.procs.2020.03.367.

[10] B. Venkatesh and J. Anuradha, "A review of Feature Selection and its methods," Cybern. Inf. Technol., vol. 19, no. 1, pp. 3-26, 2019, doi: 10.2478/CAIT-2019-0001.

[11] I. Sumaiya Thaseen and C. Aswani Kumar, "Intrusion detection model using fusion of chisquare feature selection and multi class SVM," J. King Saud Univ. - Comput. Inf. Sci., vol. 29, no. 4, pp. 462-472, 2017, doi: 10.1016/j.jksuci.2015.12.004.

[12] D. B. Satmoko, P. Sukarno, and E. M. Jadied, "Peningkatan Akurasi Pendeteksian Serangan DDoS Menggunakan Multiclassifier Ensemble Learning dan Chi-Square," vol. 5, no. 3, pp. 7977-7985, 2018.

[13] J. Gu and S. Lu, "An effective intrusion detection approach using SVM with naïve Bayes feature embedding," Comput. Secur., vol. 103, p. 102158, 2021, doi: 10.1016/j.cose.2020.102158.

[14] T. M. Oshiro, P. S. Perez, and J. A. Baranauskas, "How many trees in a random forest?," Lect. Notes Comput. Sci. (including Subser. Lect. Notes Artif. Intell. Lect. Notes Bioinformatics), vol. 7376 LNAI, pp. 154-168, 2012, doi: 10.1007/978-3-642-31537-4_13.

[15] K. Shah, H. Patel, D. Sanghvi, and M. Shah, "A Comparative Analysis of Logistic Regression, Random Forest and KNN Models for the Text Classification," Augment. Hum. Res., vol. 5, no. 1, 2020, doi: 10.1007/s41133-020-00032-0.

[16] B. P. O. Lovatti, M. H. C. Nascimento, Á. C. Neto, E. V. R. Castro, and P. R. Filgueiras, "Use of Random forest in the identification of important variables," Microchem. J., vol. 145, no. December 2018, pp. 1129-1134, 2019, doi: 10.1016/j.microc.2018.12.028.

[17] S. K. Lakshmanaprabu, K. Shankar, M. Ilayaraja, A. W. Nasir, V. Vijayakumar, and N. Chilamkurti, "Random forest for big data classification in the internet of things using optimal features," Int. J. Mach. Learn. Cybern., vol. 10, no. 10, pp. 2609-2618, 2019, doi: 10.1007/s13042-018-00916-z.

[18] Z. Noshad et al., "Fault detection in wireless sensor networks through the random forest classifier," Sensors (Switzerland), vol. 19, no. 7, pp. 1-21, 2019, doi: 10.3390/s19071568. 